\title{
Defective Urinary Crystallization Inhibition and Urinary Stone Formation
}

\author{
Mauricio Carvalho, Jody P. Lulich, Carl A. Osborne, Yasushi Nakagawa
}

Kidney Stone Program (YN, MC), Division of Biological Sciences and the Pritzker School of Medicine, University of Chicago, Chicago, Illinois, USA, Department of Small Animal Clinical Sciences (JPL, CAO), College of Veterinary Medicine, University of Minnesota, St. Paul, Minnesota, USA, and Department of Internal Medicine (MC), Federal University of Parana, Curitiba, Parana, Brazil

\begin{abstract}
Introduction: Nephrocalcin (NC) is a glycoprotein produced in the kidney and inhibits calcium oxalate crystal formation. It has been separated into 4 isoforms $(A, B, C$, and D) and found that $(A+B)$ are more abundant than $(C+D)$ in urine of healthy subjects, but the reverse is seen in human urine of kidney stone patients. To further examine the role of this protein in inhibition of urinary crystallization, nephrocalcin isoforms were purified from 2 genetically pure dog species.

Materials and Methods: We studied healthy Beagles, known to be non-stone forming dogs, and Mini-Schnauzers, known to be calcium oxalate stone formers. NC was isolated and purified from each group. Urinary biochemistry and calcium oxalate crystal growth inhibition were measured.

Results: Specific crystal growth inhibition activity was significantly higher in non-stone forming dogs $(9.79 \pm 2.25$ in Beagles vs. $2.75 \pm 1.34$ of Mini-Schnauzers, $\mathrm{p}<0.005$ ). Dissociation constants toward calcium oxalate monohydrate were 10-fold different, with Beagles' isoforms being 10 times stronger inhibitors compare to those of Mini-Schnauzers'. Isoforms $\mathrm{C}+\mathrm{D}$ of $\mathrm{NC}$ were the main isoforms isolated in stone-forming dogs.

Conclusion: NC of these two species of dogs differently affects calcium oxalate crystallization and might have a role in determining ulterior urinary stone formation.
\end{abstract}

Key words: kidney stone; calcium oxalate; crystallization; experiments; dogs

Int Braz J Urol. 2006; 32: 342-9

\section{INTRODUCTION}

Normal urine is supersaturated with respect to crystalline components, as a consequence of the essential homeostatic water conservation. This condition suggests the existence of physiological mechanisms that actively inhibit urinary crystallization of calcium salts (1). Various inhibitory macromolecules have been implicated in this process, e.g. osteopontin, crystal matrix protein, bikunin and nephrocalcin.

Nephrocalcin (NC) was isolated from human urine and kidney tissues (2), and later found in urine of 9 vertebrates' species (3). This glycoprotein is produced in proximal tubules in kidney (4) and its excretion is increased in renal carcinoma patients (5) and during pregnancy (6). NC has a mol. wt. of 14 $\mathrm{kD}$, and can be separated into 4 isoforms with differ- 
ent degrees of phosphorylation and amphiphilicities (7). Healthy subjects excrete more isoforms A and B that are less phosphorylated and have stronger hydrophobicity properties. In contrast, kidney stone forming patients excrete more isoforms $-\mathrm{C}$ and $-\mathrm{D}$, which have higher degree of phosphorylation and weaker hydrophobicity. These isoforms of NC coat the surface of calcium oxalate crystals and control morphology, size and surface topography of crystals (8).

Evidence suggests that defective inhibitors can cause nephrolithiasis and NC accounts for a considerable portion of the inhibitory property of crystallization in urine (9). To examine this premise, we evaluated two species of pure-breed dogs with different incidences of kidney stones. We purified NC from urine samples from Beagles dogs, a non-stone forming species (10) and from Mini-Schnauzer dogs, known for frequent formation of calcium oxalate stones $(11,12)$. In this report we compared chemical and physicochemical properties of NCs isolated from these species.

\section{MATERIALS AND METHODS}

Eleven healthy Beagles ( 3 neutered males and 8 neutered females, $4.0 \pm 0.4$ years old, body weight $9.28 \pm 0.36 \mathrm{~kg}$ ), and 7 Mini-Schnauzers (4 neutered males and 3 neutered females, 2.5 to 10.5 years old, body weight $6.6 \pm 1.9 \mathrm{~kg}$, who had at least one urinary stone) were selected. They were housed in individual cages under the conditions of controlled lighting and temperature, at the College of Veterinary Medicine, the University of Minnesota, according to the principles outlined in the National Institutes of Health "Guide for the Care and Use of Laboratory Animals".

At the beginning of collection period, the urine from the bladders of dogs was emptied by transurethral catheterization. They were then housed in metabolic cages to facilitate complete collection of voided urine. Water was accessible throughout the collection period. Urine was collected in plastic containers surrounded by ice and stored in capped plastic containers with thymol at $4^{\circ} \mathrm{C}$. To ensure com- plete removal of urine, dogs were catheterized at the end of $24 \mathrm{~h}$. To minimize catheter induced bacterial urinary tract infection, cefadroxil ${ }^{\circledR}$ was administered orally $(20 \mathrm{mg} / \mathrm{kg}, \mathrm{q} 12 \mathrm{~h}$ ) during the $24 \mathrm{~h}$ period of urine collection (13). Refrigerated urine samples were warmed at room temperature. Urine $\mathrm{pH}$ was measured by using a Beckman pHmeter. Calcium, citrate, creatinine, oxalate, phosphate, and uric acid were determined by using a Beckman CX-5 autoanalyzer. Protein was determined in urine by micro-Lowry method using Folin-Ciocalteu Phenol reagent (14). Bovine serum albumin was used as a calibration standard with a concentration range between 10 to $50 \mu \mathrm{g}$.

$\mathrm{NC}$ was isolated and purified by the method previously described (15). Briefly, urine was diluted 3 -fold by distilled water, $\mathrm{pH}$ adjusted to 7.3 , and added $1 / 10$ volume of DEAE-cellulose pre-equilibrated in $0.05 \mathrm{M}$ Tris- $\mathrm{HCl}, \mathrm{pH}$ 7.3, then stirred gently for 30 min at room temperature. The DEAE cellulose was separated by filtering through Whatman \#1 filter paper with a Buchner funnel. The DEAE-cellulose cake was then washed with $1 \mathrm{~L}$ of $0.05 \mathrm{M}$ Tris- $\mathrm{HCl}, \mathrm{pH} 7.3$ containing $0.1 \mathrm{M} \mathrm{NaCl}$ (Buffer-A). NC was eluted by $200 \mathrm{~mL}$ of $0.05 \mathrm{M}$ Tris- $\mathrm{HCl}, \mathrm{pH} 7.3$ containing $0.5 \mathrm{M}$ $\mathrm{NaCl}$ (Buffer-B) with gentle stirring for $30 \mathrm{~min}$ at room temperature. The filtrated NC fraction was dialyzed against $10 \mathrm{~L}$ of distilled water overnight with 1 change. The dialyzed fraction was further subjected to a DEAEcellulose column $(2 \times 15 \mathrm{~cm})$, and $4 \mathrm{NC}$ isoforms (A,B,C, and $\mathrm{D})$ were isolated by a linear $\mathrm{NaCl}$ gradient using $125 \mathrm{~mL}$ each of Buffer-A and Buffer-B. The salt gradient was monitored by a conductivity meter (Radiometer CDM210). The quantity of the individual isoform inhibition as measured under the curve was calculated and expressed as a relative ratio of inhibitory activity by percentage. Each of the four NC isoforms was further purified by a molecular sieve column of BioRad P-10 column ( 2 x $85 \mathrm{~cm}$ ) using 50\% formamide for separating urobilirubin from nephrocalcin, then followed by Sephacryl S-200 (1 x $90 \mathrm{~cm}$ ) using Buffer-A. Purified NC concentration was determined by an alkaline hydrolysis followed by a ninhydrin reaction (7). Phosphoric acid content was determined by the method described by Ames (16). The color was developed by using Fiske-Subbarow reagent and $0.01 \mathrm{M} \mathrm{KH}_{2} \mathrm{PO}_{4}$ was used for preparing a 
calibration standard ranging between 50 to $500 \mu$ moles of phosphate concentration.

Surface tension at the air-water interface was measured by Lauda film balance (Brinkman Instruments Co., Westbury, NY) using 0.01 M Tris- $\mathrm{HCl}$, $\mathrm{pH} 7.4$, containing $0.1 \mathrm{M} \mathrm{NaCl}$, and applied $100 \mu \mathrm{g}$ of protein over the surface of the buffer solution. The protein film was compressed from the surface area of $327 \mathrm{~cm}^{2}$ to $18 \mathrm{~cm}^{2}$ in $30 \mathrm{~min}$ and the pressure changes were monitored and recorded through a computer.

Calcium oxalate crystal growth inhibition was measured by either ${ }^{14} \mathrm{C}$-calcium oxalate incorporation method (15) or spectrophotometric method measuring decrease of oxalic acid (2). In brief, ${ }^{14} \mathrm{C}$-calcium oxalate incorporation assay was done by mixing $500 \mu \mathrm{L}$ of sodium acetate buffer $(50 \mathrm{mM}$ acetic acid, $5 \mathrm{mM}$ barbituric acid, $0.15 \mathrm{M} \mathrm{NaCl}$, pH 5.7 containing 0.05 $\mu \mathrm{Ci} / \mathrm{mL}$ of ${ }^{14} \mathrm{C}$-oxalic acid), $500 \mu \mathrm{L}$ of calcium chloride solution $\left(50 \mathrm{mM}\right.$ acetic acid, $2 \mathrm{mM} \mathrm{CaCl}_{2} .2 \mathrm{H}_{2} \mathrm{O}$, $0.13 \mathrm{M} \mathrm{NaCl}, 5 \mathrm{mM}$ barbituric acid, $\mathrm{pH} 5.7$ ) and 25 $\mu \mathrm{L}$ of a sample solution. The crystallization is initiated by adding $100 \mu \mathrm{L}$ of calcium oxalate monohydrate crystal slurry $(1.8 \mathrm{mg} / \mathrm{mL}$ in sodium acetate buffer, $\mathrm{pH} 5.7)$. After 40 minutes of incubation, the mixture was centrifuged, and radioactivity was measured in the supernatant. Inhibitory activity is calculated as the following equation: $\mathrm{I}=\left(\mathrm{C}_{40}-\mathrm{C}_{\text {blank }}\right) /\left(\mathrm{C}_{0}-\mathrm{C}_{40}\right) \cdot\left(\mathrm{C}_{\text {blank }}\right)$ radioactivity of buffer solution; $\mathrm{Co}$ : radioactivity counts at initial time, $\mathrm{C}_{40}$ : radioactivity count in the supernatant after $40 \mathrm{~min}$ incubation. Spectrophotometric assay was performed as following: $1 \mathrm{~mL}$ of sodium oxalate was added to acetate buffer $(8.75 \mathrm{mM}$ acetic acid and 90 $\mathrm{mM} \mathrm{NaCl}, \mathrm{pH}$ 5.7) and to a calcium chloride solution in a cuvette, with an aliquot of the sample solution. While this mixture was stirring, $10 \mu \mathrm{L}$ of calcium oxalate monohydrate slurry in acetate buffer $(0.8 \mathrm{mg}$ calcium oxalate monohydrate $/ \mathrm{mL}$ of acetate buffer) was collected to the spectrophotometric analysis. As oxalic acid consumed to forming calcium oxalate, absorbance at $214 \mathrm{~nm}$ decreases. The slope of the curve reflects the strength of crystal growth inhibitory activity of a sample, and also the dissociation constant of an isolated inhibitor can be calculated by plotting a Langmuir isotherm type plot. Amino acid composition was determined by a Beckman amino acid analyzer (Model 119CL, Beckman Instruments, Palo Alto, CA), after hydrolysis in an evacuated tube containing $6 \mathrm{~N}$ $\mathrm{HCl}$ for $24 \mathrm{hrs}$ at $11^{\circ} \mathrm{C}$. Neutral sugar analysis was carried out by phenol- $\mathrm{H}_{2} \mathrm{SO}_{4}$ method (17). Calibration curve was made by using 5 to $20 \mu \mathrm{g}$ of glucose aqueous solution. Molecular weight was determined by HPLC with a molecular sieve column (TSK-2000SW, ToSoHaas, Montogomeryville, PA). Molecular weight standards used were BSA, soybean trypsin inhibitor, and cytochrome $\mathrm{C}$. The solvent used was a Buffer-B, and running conditions were isocratic mode, flow rate $1.0 \mathrm{~mL} / \mathrm{min}$, and detection wavelength at $220 \mathrm{~nm}$.

Results are expressed as means \pm SD. Statistical analyses were performed using Minitab 11.0 software. Group differences were compared by unpaired t-test and the frequency of nephrocalcin isoforms by $\chi^{2}$-statistical analysis. A value of $\mathrm{p}<0.05$ was considered significant.

\section{RESULTS}

Urine of individual dogs was analyzed and averaged values of $\mathrm{pH}$, calcium, phosphate, uric acid, citrate, oxalate, and protein are summarized in Table1. There were significant differences in calcium and uric acid excretion between Mini-Schnauzers and Beagles ( $\mathrm{p}<0.005)$.

Urinary protein concentration and crystal growth inhibition activities of both species were compared in Table-2. The specific inhibitory activity of non-stone forming dogs (Beagles) was approximately

Table 1 - Urine biochemistry. Concentrations are expressed as $m g / c r e a t i n i n e ~ b a s i s$.

\begin{tabular}{lcc}
\hline & $\begin{array}{c}\text { Mini-Schnauzers } \\
(\mathrm{n}=7)\end{array}$ & $\begin{array}{c}\text { Beagles } \\
(\mathrm{n}=11)\end{array}$ \\
\hline $\mathrm{pH}$ & $6.53 \pm 0.72$ & $6.79 \pm 0.32$ \\
Protein & $0.03 \pm 0.01$ & $0.02 \pm 0.02$ \\
Calcium* & $0.07 \pm 0.02$ & $0.03 \pm 0.02$ \\
Uric acid* & $0.17 \pm 0.05$ & $0.07 \pm 0.02$ \\
Phosphate & $0.52 \pm 0.48$ & $0.95 \pm 0.38$ \\
Oxalate & $0.04 \pm 0.06$ & $0.05 \pm 0.01$ \\
Citrate & $0.28 \pm 0.40$ & $0.12 \pm 0.10$ \\
\hline
\end{tabular}

* Mini-Schnauzers vs. Beagles; $p<0.005$. 
Table 2 - Comparisons of urinary protein concentration and calcium oxalate crystal inhibition activity.

\begin{tabular}{lcc}
\hline & $\begin{array}{c}\text { Protein } \\
\text { Concentration } \\
(\mathrm{mg} / \mathrm{mL})\end{array}$ & $\begin{array}{c}\text { Specific Crystal } \\
\text { Growth } \\
\text { Inhibition Rate }\end{array}$ \\
\hline Beagles & $0.21 \pm 0.05$ & $9.79 \pm 2.25$ \\
Mini-Schnauzers* & $0.23 \pm 0.11$ & $2.75 \pm 1.34$ \\
\hline
\end{tabular}

*Inhibition rate, Beagles vs. Mini-Schnauzers; $p<0.005$.

4 times higher than stone forming dogs (Mini-Schnauzers).

Elution patterns of $\mathrm{NC}$ isoforms $\mathrm{A}, \mathrm{B}, \mathrm{C}$, and $\mathrm{D}$ are summarized in Table-3. Non-stone forming Beagles excreted in their urine $56 \%$ of isoforms (A+ B), and $44 \%$ of $(C+D)$ isoforms. Particularly, B isoform peaked in the isoforms isolated. The ratios of isoforms in the Mini-Schnauzers dogs were $43 \%$ of isoforms $(A+B)$ and $57 \%$ of isoforms $(C+D)$. In this group, $\mathrm{C}$ was the main isoform isolated.
Carbohydrate content was measured by phenol-sulfonic acid method and calculated by molar ratio per protein (Table-4). All isoforms contained 0.01 to $0.02 \mathrm{~g}$ per gram of protein. Dogs urinary NC showed high content of acidic amino acid residues and low content of aromatic and basic amino acid residues. However, both species showed almost identical amino acid compositions. On the other hand, phosphate content in Mini-Schnauzers' NC was significantly higher compared to Beagles (Table-4).

Figure-1 shows typical force area curves of these isoforms at the air-water interface measured by a Lauda film balance. Isoform A of the Beagles showed the highest collapsing pressure, $44.8 \mathrm{mN} / \mathrm{m}$, and gradual decreases were seen in B,C and D. MiniSchnauzers showed lower collapse pressure in isoforms A and higher collapse pressure in isoforms $\mathrm{C}$ and $\mathrm{D}$ when compared to the Beagles' group. Table4 summarizes collapsing pressure and dissociation constants of $4 \mathrm{NC}$ isoforms isolated from both species.

Table 3 - Distribution ratios (\%) of 4 nephrocalcin isoforms.

\begin{tabular}{lllll}
\hline & Isoform-A & Isoform-B & Isoform-C & Isoform-D \\
\hline Beagles $(\mathrm{n}=11)^{*}$ & $11.45 \pm 4.25$ & $44.42 \pm 14.31$ & $21.05 \pm 6.74$ & $21.90 \pm 13.37$ \\
Mini-Schnauzers $(\mathrm{n}=7)$ & $17.80 \pm 6.41$ & $26.79 \pm 11.36$ & $32.91 \pm 14.13$ & $18.19 \pm 6.95$ \\
\hline
\end{tabular}

*Beagles vs. Mini-Schnauzers IsoA + IsoB, $p<0.05$

Table 4 - Chemical composition and physical properties of 4 NC-Isoforms.

\begin{tabular}{lccccccccc}
\hline & \multicolumn{4}{c}{ Beagles } & \multicolumn{5}{c}{ Mini-Schnauzers } \\
\hline Isoform & $\mathbf{A}$ & $\mathbf{B}$ & $\mathbf{C}$ & $\mathbf{D}$ & $\mathbf{A}$ & $\mathbf{B}$ & $\mathbf{C}$ & $\mathbf{D}$ \\
Carbohydrate & 0.01 & 0.02 & 0.02 & 0.02 & 0.02 & 0.01 & 0.01 & 0.02 \\
Phosphate & 0.52 & 1.30 & 1.72 & 3.24 & 1.72 & 2.48 & 4.42 & $12.96^{*}$ \\
Collapse pressure & $44.8^{* *}$ & $40.8^{* *}$ & 27.4 & 31.0 & 35.8 & 31.2 & 33.7 & 36.9 \\
Dissociation & 8.38 & 7.94 & 3.28 & 6.73 & 3.32 & 1.47 & 2.28 & 2.80 \\
Constant** & $\mathrm{x} 10^{-7} \mathrm{M}$ & & & & $\mathrm{x} 10^{-6} \mathrm{M}$ & & &
\end{tabular}

*Mini-Schnauzers vs. Beagles $p<0.005 ; * *$ Mini-Schnauzers vs. Beagles $p<0.05$. Carbohydrate and phosphate are expressed in molar ratio to protein. Collapse pressure $(\mathrm{Nm} / \mathrm{m})$ was measured by a Lauda film balance. Dissociation constant toward calcium oxalate monohydrate crystals was determined by a spectrophotometric method and calculated from Langmuir isotherm type plot. 

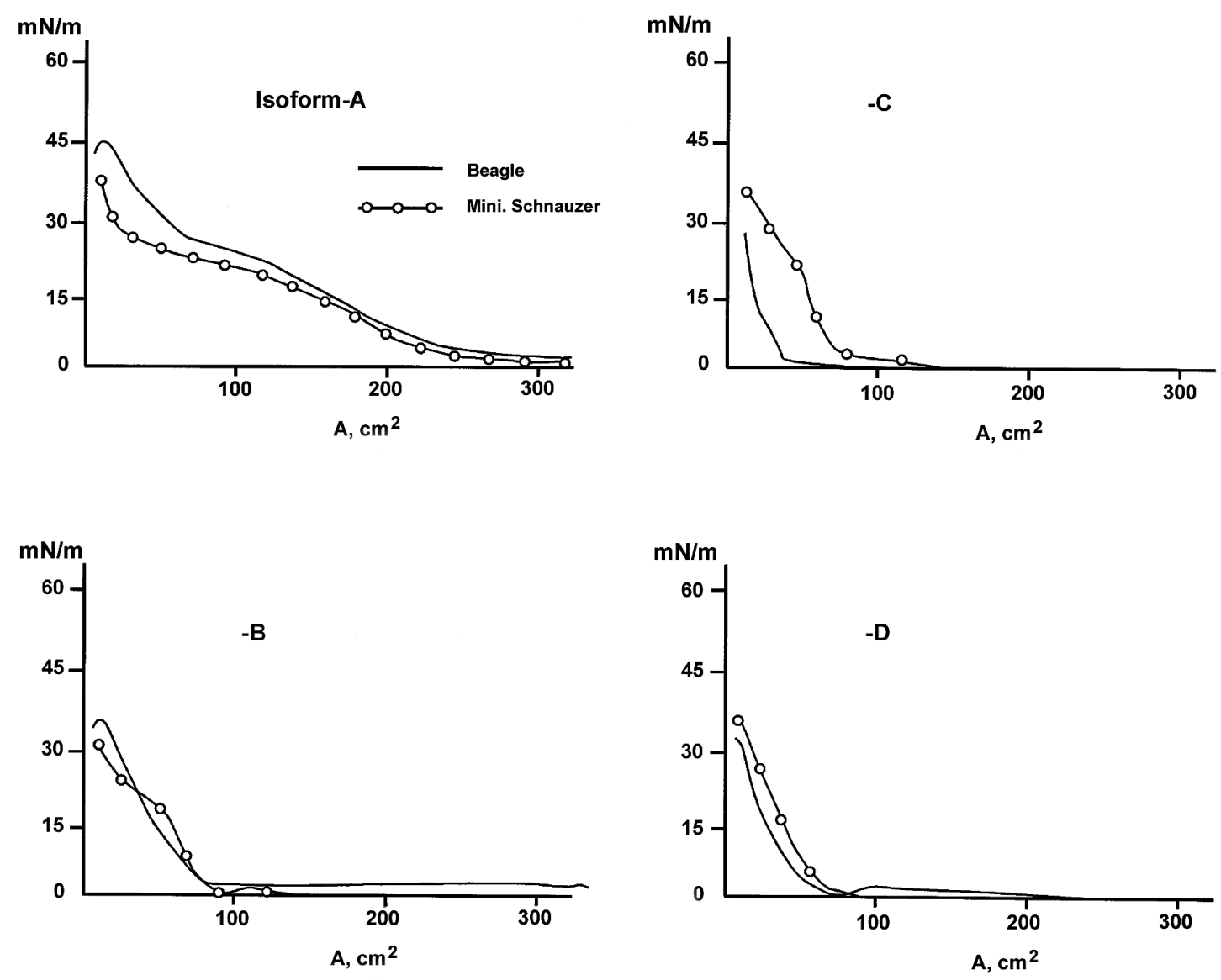

Figure 1 - A force area curve of isolated isoforms at the air-water interface measured by Laud film balance. Experimental details are described in Materials and Methods section.

\section{COMMENTS}

It has been accepted that stone formation is a crystallization process, taking place in supersaturated urine. However, despite nearly universal urine supersaturation, stones occur in a minority of people. Crystallization inhibitors, like citrate, proteins and glycosaminoglycans may account for this discrepancy (18). In this study, using two different species of dogs with distinct incidences of urinary stones several conclusions can be reached.

Mini-Schnauzers, a class of dogs with high formation of kidney stones, excreted more calcium and uric acid in their urine $(\mathrm{p}<0.005)$ when compared to Beagle's group, a species that rarely presents with nephrolithiasis. These electrolytes combine to promote higher supersaturated urine, certainly predisposing these dogs to urinary stone formation.

However, we also found a remarkable difference in the qualitative excretion of urinary $\mathrm{NC}$ between these dogs' breeds. The NC isolated from the urine of Beagles showed strong inhibitory activity toward calcium oxalate crystals, but Mini-Schnauzers' urine has 4 times less inhibitory activity (Table-2). Previously we reported the same pattern of data in humans with or without urinary stones (7).

Non-stone forming Beagles' excreted in their urine more $\mathrm{NC}$ isoforms $\mathrm{A}$ and $\mathrm{B}$ than isoforms $\mathrm{C}$ and $\mathrm{D}$ when compared to Mini-Schnauzers ( $\mathrm{p}<0.05$ ). $\mathrm{NC}$ isoforms are calcium-binding proteins, and binds 
4 atoms of calcium ions per one molecule of NC. The $\mathrm{Ca}^{2+}$ binding mode is significantly different between isoform $\mathrm{A}$ or $\mathrm{B}$ and $\mathrm{C}$ or D: isoforms A-B binds $\mathrm{Ca}^{2+}$ directly through carboxyl groups of asp and/or glu residues. However, isoforms C-D requires at least two molecules of water between $\mathrm{Ca}^{2+}$ and carboxyl groups (19). Isoforms $\mathrm{A}$ and $\mathrm{B}$ changes its conformation and increase its hydrophobicity upon binding $\mathrm{Ca}^{2+}$, but isoforms $\mathrm{C}$ or $\mathrm{D}$ do not. As a consequence isoforms $\mathrm{C}$ and $\mathrm{D}$ are more soluble in water and forms a less stable monolayer at the interface of air-water, and the collapsing pressure is lower. Less hydrophobicity of isoforms $\mathrm{C}$ and $\mathrm{D}$ might be related to a higher content of phosphate residues. In resume, we can say that in the current study we found the presence of a larger quantity of "good" inhibitors in Beagles' urine when compared to the group of Mini-Schnauzers dogs. Our classification of "good" inhibitors is based on different hydrophobicity, charge of the molecule and phosphate content. We can speculate at this moment that the isoforms that acts as strong (A-B) or weak (C-D) inhibitors of calcium oxalate crystallization are the same protein with different post-transcriptional modifications.

Finally, we found another indication of better inhibitory performance in the NC isolated from the urine of Beagles' group. When compared to the stone forming Mini-Schnauzer's dogs, dissociation constants toward $\mathrm{CaOx}$ monohydrate crystals for Beagles NC isoforms are 10-fold higher than those of stone forming dogs' isoforms. This means that they are at least 10-fold stronger in binding capacity to the $\mathrm{CaOx}$ crystal surface when compared to those of the Mini-Schnauzer NC.

We would like to point some limitations of our work. We did not study others inhibitors like glycosaminoglycans or Tamm-Horsfall protein, for example. However, we $(20,21)$ have showed that almost $80 \%$ of inhibitory crystallization of calcium oxalate in urine is due to NC. Also, we made some inter-species analysis without using controls in each group. Nonetheless, this work can be considered as a pilot study and supported by these findings inter- and intra-species assessments will be the theme of a future analysis. Finally, our findings are not necessarily applicable to human nephrolithiasis. But in some cases animals' models of nephrolithiasis have close pathogenetic association to kidney stone formation in humans $(22,23)$.

\section{CONCLUSION}

Nephrocalcin isolated from urine samples of Beagles dogs, a non-stone forming species, and from Mini-Schnauzer dogs, known for frequent formation of calcium oxalate stones, differently affected calcium oxalate crystallization and might have a role in determining urinary stone formation.

\section{ACKNOWLEDGMENT}

Yasushi Nakagawa thanks Prof. W. Cho, Chemistry Department, the University of Illinois at Chicago, for using a Lauda film balance and for useful suggestions.

\section{CONFLICT OF INTEREST AND FINANCIAL SUPPORT}

This research was supported by Morris Animal Foundation, Englewood, $\mathrm{CO}$ and Hill's Nutrition Inc., Topeka, KS (JPL and CAO, University of Minnesota).

\section{REFERENCES}

1. Mazzali M, Kipari T, Ophascharoensuk V, Wesson JA, Johnson R, Hughes J: Osteopontin-a molecule for all seasons. QJM. 2002; 95: 3-13.

2. Nakagawa Y, Ahmed M, Hall SL, Deganello S, Coe FL.: Isolation from human calcium oxalate renal stones of nephrocalcin, a glycoprotein inhibitor of calcium oxalate crystal growth. Evidence that nephrocalcin from patients with calcium oxalate nephrolithiasis is deficient in gamma-carboxyglutamic acid. J Clin Invest. 1987; 79: 1782-7.

3. Nakagawa Y, Renz CL, Ahmed M, Coe FL: Isolation of nephrocalcin from kidney tissue of nine vertebrate species. Am J Physiol. 1991; 260: F243-8. 
4. Sirivongs D, Nakagawa Y, Vishny WK, Favus MJ, Coe FL: Evidence that mouse renal proximal tubule cells produce nephrocalcin. Am J Physiol. 1989; 257: F390-8.

5. Nakagawa Y, Sirivongs D, Novy MB, Netzer MF, Michaels E, Vogelzang NJ, et al.: Nephrocalcin: biosynthesis by human renal carcinoma cells in vitro and in vivo. Cancer Res. 1992; 52: 1573-9.

6. Davison JM, Nakagawa Y, Coe FL, Lindheimer MD: Increases in urinary inhibitor activity and excretion of an inhibitor of crystalluria in pregnancy: a defense against the hypercalciuria of normal gestation. Hypertens Pregnancy. 1993; 12: 25-35.

7. Nakagawa Y, Abram V, Parks JH, Lau HS, Kawooya JK, Coe FL: Urine glycoprotein crystal growth inhibitors. Evidence for a molecular abnormality in calcium oxalate nephrolithiasis. J Clin Invest. 1985; 76: 1455-62.

8. Kurutz JW, Carvalho M, Nakagawa Y: Nephrocalcin isoforms coat crystal surfaces and differentially affect calcium oxalate monohydrate crystal morphology, growth, and aggregation. J Cryst Growth. 2003; 255: 392-402.

9. Carvalho M, Mulinari RA, Nakagawa Y: Role of Tamm-Horsfall protein and uromodulin in calcium oxalate crystallization. Braz J Med Biol Res. 2002; 35: 1165-72.

10. Kaspar LV, Poole CM, Norris WP: Incidence of struvite urinary calculi in two ancestral lines of beagles. Lab Anim Sci. 1978; 28: 545-50.

11. Houston DM, Moore AE, Favrin MG, Hoff B: Canine urolithiasis: A look at over 16000 urolith submissions to the Canadian Veterinary Urolith Centre from February 1998 to April 2003. Can Vet J. 2004; 45: 223-30.

12. Lulich JP, Osborne CA, Unger LK, Sanna J, Clinton CW, Davenport MP: Prevalence of calcium oxalate uroliths in miniature schnauzers. Am J Vet Res. 1991; 52: 1579-82.

13. Osborne, CA: Techniques of urine collection and preservation. In: Osborne, CA and Finco DR (ed.), Canine and feline Nephrology and Urology. Philadelphia, PA, Williams and Wilkins. 1995; pp. 100-21.
14. Peterson GL: Determination of total protein. Methods Enzymol. 1983; 91: 95-119.

15. Nakagawa Y, Abram V, Kezdy FJ, Kaiser ET, Coe FL: Purification and characterization of the principal inhibitor of calcium oxalate monohydrate crystal growth in human urine. J Biol Chem. 1983; 258: 12594-600.

16. Ames BN, Dubin D: The role of polyamines in the neutralization of bacterophage deoxyribonucleic acid. J Biol Chem. 1960; 235: 769-75.

17. Chaplin MF: Monosaccharides. In: Chaplin MF, Kennedy JF (ed.), Carbohydrate analysis. Washington, DC, IRL Press. 1986; pp. 1-36.

18. Carvalho M, Vieira MA: Changes in calcium oxalate crystal morphology as a function of supersaturation. Int Braz J Urol. 2004; 30: 205-8; discussion 209.

19. Mustafi D, Nakagawa Y: Characterization of $\mathrm{Ca}(2+)-$ binding sites in the kidney stone inhibitor glycoprotein nephrocalcin using vanadyl ions: different metal binding properties in strong and weak inhibitor proteins revealed by EPR and ENDOR. Biochemistry. 1996; 35: 14703-9.

20. Coe FL, Nakagawa Y, Asplin J, Parks JH: Role of nephrocalcin in inhibition of calcium oxalate crystallization and nephrolithiasis. Miner Electrolyte Metab. 1994; 20: 378-84.

21. Worcester EM, Nakagawa Y, Wabner CL, Kumar S, Coe FL: Crystal adsorption and growth slowing by nephrocalcin, albumin, and Tamm-Horsfall protein. Am J Physiol. 1988; 255: F1197-205.

22. Carvalho M, Lulich JP, Osborne CA, Nakagawa Y: Role of urinary inhibitors of crystallization in uric acid nephrolithiasis: Dalmatian dog model. Urology. 2003; 62: 566-70.

23. Ombra MN, Casula S, Biino G, Maestrale G, Cardia F, Melis P, et al.: Urinary glycosaminoglycans as risk factors for uric acid nephrolithiasis: case control study in a Sardinian genetic isolate. Urology. 2003; 62: 41620.

Accepted after revision:

February 27, 2006 


\section{EDITORIAL COMMENT}

Nucleation, growth and aggregation are the principal crystallization mechanisms in stone development (1). Urine contains compounds that modulate such processes as well as the attachment of crystals to renal epithelial cells. While nucleation promotion activity is most likely sustained by membrane lipids, most of the inhibitory aggregation activity resides in macromolecules such as glycoproteins and glycosaminoglycans (2). Inhibitory proteins found in urine include nephrocalcin, Tamm-Horsfall glycoprotein (THG), prothrombin fragment 1, bikunin (uronic acid-rich protein), osteopontin, inter- $\alpha$-trypsin inhibitor, among others. Most of the molecules are anionic, with many acidic amino acid residues, frequently contain post-translational modifications such as phosphorylation and glycosylation, and appear to exert their effects by binding to calcium oxalate surface (3). The specific structural motifs that favor crystal binding and inhibition are not yet known. A number of proteins are made by renal epithelial cells, whereas others gain access to the urine by glomerular filtration. In a number of cases, abnormalities of protein structure or function have been found in stone formers. It is not yet known what proportion of stone formers have an abnormality of inhibitor function (3).

Nephrocalcin, first described by Nakagawa et al. (4), has subsequently been shown in studies by the same group, to be deficient in gammacarboxyglutamic acid in patients with calcium oxalate nephrolithiasis $(5,6)$, hence reducing its ability to inhibit $\mathrm{CaOx}$ crystallization. According to Ryall (7), the fact that this protein has not been sequenced yet may raise some questions about it being possibly related to bikunin, a fragment of inter- $\alpha$-trypsin inhibitor (8).

In this issue, Carvalho et al. compared biochemical and physicochemical properties of $\mathrm{NC}$ in 2 species of dogs that form (Mini-Schnauzers) or do not form (Beagles) calcium oxalate stones. They con- cluded that the specific crystal growth inhibition activity was significantly higher in the latter, which also possessed the isoforms usually not implicated in stone formation. Although these findings may not be applicable to human nephrolithiasis, it sheds further light into the understanding of how crystallization inhibitors may ultimately affect stone formation.

\section{REFERENCES}

1. Kavanagh JP: Enlargement of a lower pole calcium oxalate stone: a theoretical examination of the role of crystal nucleation, growth, and aggregation. J Endourol. 1999; 13: 605-10.

2. Khan SR, Kok DJ: Modulators of urinary stone formation. Front Biosci. 2004; 9: 1450-82.

3. Worcester EM: Inhibitors of stone formation. Semin Nephrol. 1996; 16: 474-86.

4. Nakagawa Y, Kaiser ET, Coe FL: Isolation and characterization of calcium oxalate crystal growth inhibitors from human urine. Biochem Biophys Res Commun. 1978; 84: 1038-44.

5. Nakagawa Y, Abram V, Parks JH, Lau HS, Kawooya JK, Coe FL: Urine glycoprotein crystal growth inhibitors. Evidence for a molecular abnormality in calcium oxalate nephrolithiasis. J Clin Invest. 1985; 76: 145562.

6. Nakagawa Y, Ahmed M, Hall SL, Deganello S, Coe FL: Isolation from human calcium oxalate renal stones of nephrocalcin, a glycoprotein inhibitor of calcium oxalate crystal growth. Evidence that nephrocalcin from patients with calcium oxalate nephrolithiasis is deficient in gamma-carboxyglutamic acid. J Clin Invest. 1987; 79: 1782-7.

7. Ryall RL: Macromolecules and urolithiasis: parallels and paradoxes. Nephron Physiol. 2004; 98: 37-42.

8. Tang Y, Grover PK, Moritz RL, Simpson RJ, Ryall RL: Is nephrocalcin related to the urinary derivative (bikunin) of inter-alpha-trypsin inhibitor? Br J Urol. 1995; 76: 425-30.

Dr. Ita Pfeferman Heilberg Associate Professor, Division of Nephrology Federal University of Sao Paulo, UNIFESP Sao Paulo, SP, Brazil E-mail: ipheilberg@nefro.epm.br 